frequency of the two enantiomorphs. We might even predict that if a chemist were to spend his life in the preparation of innumerable and smallest physically sensible amounts of a normally racemoid substance, he would with fine enough apparatus ultimately be able to detect some amount of rotatory polarisation. In nature, where during countless ages (and in the past probably much more actively than at preseni) inorganic actions and reactions have taken place without man's aid, the production of chemical compounds of one-sided asymmetry must, on Prof. Japp's view of the relation of mechanical action to chance, undoubtedly have taken place. Further, according to Prof. Japp's fourth principle, we may look upon such asym. metrical compounds when they have once arisen as "breeders," or endowed with a power of selecting their own kind of asymmetry from other racemoid substances. Let us put this further statement on one side, however, and content ourselves solely with dissent from Prof. Japp's view expressed in the words :

"But the chance synthesis of the simplest optically actire compound from inorganic materials is absolutely inconceivable. So also is the separation of two crystallised enantiomorphs under purely symmetric conditions."

On the contrary, if the theory expounded by Prof. Japp be correct, the inorganic origin of optically active compounds is not only conceivable, but it has a degree of probability which, how. ever small, might be calculated when we know what is the minimum number of molecules in a physically just sensible solution, and what is the majority of enantiomorphs of one kind which will give a just measurable amount of rotatory polarisation.

It will indeed be a great gain if Prof. Japp's address calls more attention to this exciting subject, and leads to further experiment and research. Karl Pearson.

\section{The Moon's Course.}

THE annual course which the moon takes in company with the earth round the sun was to me a long time a great puzzle, as it is to many others, until one day I demonstrated it to myself by the simplest method. Those who have some smatter. ing of the heavenly bodies generally fail in their attempt to draw the moon's orbit; they find no explanation in popular works, and even in books written by well-known authors the subject of the moon's motion is altogether ignored. All that is found is a circle showing the moon's phases, and it is this circle which is fatal to the conception of the true orbit of the moon : even very young readers see the impossibility of a dozen or thirteen circles surrounding the sun.

For myself, failing to find assistance in books, I readily solved the problem by a practical method, I took a piece of wire and placed a cork on each end. I then drew a line on the table and advanced one, which I called the earth, along the line; the other cork necessarily followed it, and at the sane time circulated round the earth in accordance with another force or motion given to it. Beginning with the moon behind the earth and making it pass to the right, both advancing forward, the moon made a curve until it reached the front of the earth, and then the Iatter still advancing, took the moon with it ; this came on its left side, and then making another curve on that side, again reached the front; the two curves completing the orbit round the earth.

IIy object in writing at the present moment is, that when so many persons are spending their holidays at the sea-side and there is much talk of the tides together with the moon, I take the opportunity of demonstrating by a similar method the moon's course on the sands. I make one person walk in a straight line, marking this with a stick, which he drags behind him, and I call him the earth. I then place another person, the moon, at a given distance from the other, telling him to advance also, and at the same time circulate round his companion. Beginning behind, and taking the right hand, he goes forward, making a curve until he gets to the front, then passes to the left side and forms another curve just as in the other experiment. The four quarters of the moon are in this manner seen, and if the second person continually faces the earth the moon's monthly revolution is also completed.

As these demonstrations are made on a plane, the experiment may also be shown in another way. I wind some wire thirteen times (the number of the lunar months) round a cylinder, and then take off the coil thus made. I pull it out into a helix and NO, I 508, VOL. 58] join the ends of the wire. The course of the moon is shown in the spiral, although no correct proportions are attempted. This also gives some idea why the moon is sometimes seen on the horizon and sometimes at the zenith; the reason of which is a great difficuity to young perople, as they find nothing about it in their books.

I make no pretence to be an astronomer or mathematician, and, indeed, it may be even a presumption to send this com. munication to a scientific journal; but if those who can teach fail to do so in popular books, there is no other method for the uninitiated to do the best for themselves. SaMUel Wilks.

\section{Grosvenor Street.}

\section{The Aurora of September 9.}

This evening, at about three minutes past eight, on looking out towards the south-west, I was struck by the appearance of a shaft of white light stretching from that direction upwards towards a point $10^{\circ}$ or $20^{\circ}$ south of the zenith, and immediately on reaching open ground, whence a wide view was obtained, became aware that a fine display of aurora borealis was in pro. gress. The shaft of light successively appeared and disappcared at intervals of a few seconds, and each time further eastwards, but each section was separated from the last by a space of unilluminated sky, as if there were regular spaces in the course of the beam incapable of being set aglow. Very soon after passing overhead the illumination became faint and disappeared eastwards, but now a strong glow appeared again near the horizon under a cloud south-west by west, and this rapidly grew upwards, repeating the phenomenon described in the first case. This occurred at least eleven or twelve times with little variation, except that the shaft became broader and more diffuse. The glow near the horizon south-west wards was always followed by the passage of the light across the sky within I to $1 \frac{1}{2}$ mins., and each travelling beam was separated from the last by an interval of $1 \frac{1}{2}$ to 2 mins. Meanwhile the sky north-westwards showed a pale white steady auroral light, which was at first attributed to the remains of twilight, but which continued to increase till about 8.30, when it was sufficiently strong to cast shadows and to show large print distinctly. This illumination extended slowly upwards from the north until it covered a great part of the sky up to the zenith, and scemed to be due to the luminosity of the great sheet of cirrus and cirrostratus which had covered the sky since $3.3^{0}$ p.m., for it exactly imitated the distribution forms of the cloud which I had noted during the afternoon. This cloud, unillum. inated, did not appreciably obscure the stars. The lacune of dark interspaces, while the surrounding sky shone with pale light, resembled bands or puffs of dark smoke, but remained fixed in the same situation, and altogether the phenomenon was strangely persistent, the only evident changes being a gradual shifting from north-west to north-east, and at about 9 p.m. a rosy streak north-eastwards. A little later fresh rays were shooting up from north-west by west, somewhat resembling those which an hour previously had emerged from south-west by west, but more steady and unbroken. At 9.55 a faint light was still to be seen in a north-westerly direction. Two hours before this grand exhibition we had been able to get a good view of the large spot on the sun, the intervening bank of cirriform cloud making his appearance through a telescope more like that of the moon. I have not seen any authoritative statements as to interruption of telegraphic messages or other magnetic disturbances coincident with or preceding the visible aurora, but no doubt some effect must have been observed.

Dunrozel, Haslemere, September 9. Rollo Russei.l.

\section{A White Sea.}

Durisg the recent voyage of the P. and O. Co. S.S. India to London I had an opportunity (owing to the kindness of Captain Worcester) of witnessing what seems to be a rare phenomenon. The commander had seen it two or three times in the course of his experience. No one else on board knew anything about it, and I should be glad of a reference to any detailed description.

At $1.30 \mathrm{a} . \mathrm{m}$. On the morning of August 22 , in the Indian Ocean, the officer in charge saw ahead what seemed to be a low mist, and into which the vessel steamed. I was called about fifteen minutes later.

The whole sea was milk-white, much more luminous than the clear, starry sky, and there was a very definite horizon. 